\title{
A LINGUAGEM NO ENSINO DE MATEMÁTICA
}

\author{
DUARTE, Paulo César Xavier ${ }^{1}$ \\ PEREIRA, César Henrique ${ }^{2}$ \\ REIS, Dalila Cristina ${ }^{2}$ \\ ROSA, Alessandra Carla da ${ }^{2}$
}

RESUMO: Esse artigo tem como principal meta enfatizar a comunicação e a linguagem na constituição do conhecimento matemático almejando despertar nos educadores um maior interesse pelo assunto. Desenvolvemos esse trabalho por meio de uma pesquisa bibliográfica, utilizando análises de livros, artigos e leituras diversas, na visão de teóricos como Zuci, Duval, Chauí, Nicolla, entre outros. Procuramos responder as perguntas que embasaram a pesquisa, a saber: qual a importância da linguagem no ensino da matemática? Como podemos contribuir para melhorar a compreensão dos conceitos expressos em linguagem matemática? Conclui-se no presente artigo que a comunicação e linguagem são essenciais para o ser humano, que a linguagem matemática é peça primordial para a compreensão dessa importante área do conhecimento, bem como educadores cientes desse papel devem estar aptos, através da busca incessante de conhecimento, a facilitar a aprendizagem dos alunos, contribuindo eficazmente para a melhoria da compreensão, por parte dos educandos, dos conceitos expressos em linguagem matemática.

Palavras-chave: Comunicação e Linguagem. Conhecimento Matemático. Linguagem Matemática.

SUMMARY: The main aim of the article is to emphasize communication and language in the mathematical knowledge and wishes to become interesting to students. The work was developed through bibliographical research, using book analysis, several readings and articles based on authors such as Zuci, Duval, Chauí, NIcolla and others. It was intended to answer the questions : what is the importance of language in mathematics teaching? How can we contribute to improve the understanding of concepts expressed in mathematical language? It was concluded that communication and language are essential to human beings, and that mathematical language is the key tool to the understanding of this important area of knowledge. Educators need to be aware and looking for knowledge, making it easy for students to learn, contributing efficiently to a better understanding by students of the concepts expressed in mathematical language.

Keywords: Communication and Language. Mathematical Knowledge. Mathematical Language.

\section{INTRODUÇÃO}

\section{CONSIDERAÇÕES INICIAIS}

Como assunto desse artigo, foi escolhido o tema: “A Linguagem no Ensino de Matemática”. A abordagem desse assunto foi decidida após análises e reflexões acerca do importante papel desempenhado pela linguagem em todos os aspectos da vida humana e, mais especificamente, no processo de aprendizagem e ensino da matemática.

É importante ter em mente que é "por meio da linguagem que a criança é exposta ao conhecimento humano e adquire conhecimentos sobre o mundo que a rodeia, aprimorando-se por meio da experiência acumulada pelo gênero humano no discurso da historia cultural". (FREITAS apud ZUCHI 2004, p.49). Assim sendo, o estudo do desenvolvimento da Linguagem no Ensino de Matemática pode mostrar-se como uma potente ferramenta para a aprendizagem da matemática, uma vez que "pode auxiliar a aprendizagem dos alunos

\footnotetext{
1 Doutorando e Mestre em Educação Matemática pela UNESP, de Rio Claro-SP. Professor Assistente de Tempo Integral do Departamento de Matemática da UNIVÁS- Universidade do Vale do Sapucaí- Pouso Alegre- MG.

${ }^{2}$ Egresso do Curso de Licenciatura em Matemática da UNIVÁS- Universidade do Vale do Sapucaí- Pouso AlegreMG.
} 
nos contextos da linguagem simbólica da matemática." (ZUCHI, 2004.p.49).

Dessa forma, tomamos como objetivo geral desse artigo enfatizar a linguagem matemática na constituição do conhecimento matemático, almejando contribuir para despertar nos educadores um maior interesse pelo assunto.

Durante esta pesquisa, os seguintes questionamentos nortearam o trabalho:

- Qual a importância da linguagem no ensino de matemática?

- Como podemos contribuir para melhorar a compreensão dos conceitos expressos em linguagem matemática?

Tais questionamentos remetem-nos a Zuchi (2004), que nos diz: "A linguagem matemática desenvolveu-se para facilitar a comunicação do conhecimento matemático entre as pessoas” (p.51).

Do mesmo modo, Menezes (apud ZUCHI, 2004) enfatiza que:

Como a matemática é uma área do saber de enorme riqueza, é natural que seja pródiga em inúmeras facetas; uma delas é, precisamente, ser possuidora de uma linguagem própria, que em alguns casos e em certos momentos históricos se confundiu com a própria matemática. Na realidade, estamos perante um meio de comunicação possuidor de um código próprio, com uma gramática, e que é utilizado por uma certa comunidade. Esta linguagem tem registros orais e escritos e, como qualquer linguagem, apresentada diversos níveis de elaboração a competência dos interlocutores: a linguagem matemática utilizada pelos "matemáticos profissionais", por traduzir idéias de alto nível, é mais exigente do que a linguagem utilizada para traduzir ideias numa sala de aula.(p.51).

Contudo, apesar da importância da linguagem no processo do aprendizado matemático, muitas vezes ela não é compreendida pelas pessoas leigas no assunto. Isso acontece geralmente devido ao excesso de simbologia usada, o que gera dificuldades de compreensão dos conceitos. Esse problema tem como causa a representação inadequada da linguagem matemática, a qual foi criada com a intenção de facilitar e não de complicar (ZUCHI, 2004). Além disso, a falta de preocupação em entender como funciona a linguagem matemática acaba também por contribuir para sua má utilização e muitas vezes falha em sua utilização.

(PEREIRA; REIS; ROSA,2009)

\section{A COMUNICAÇÃo}

Terra e Nicola (apud ZUCHI, 2004, p.49) definem como comunicação "o ato de tornar comum, conhecido". Na visão de Faraco e Moura (1997), “A comunicação depende de linguagens que são sistemas organizados de sinais criados pelo homem" (p.21).

É corrente a concepção de que a comunicação faz parte da vida do ser humano desde o surgimento da humanidade e que simplesmente o ato de nos comunicarmos é importante, pois é através da comunicação que o homem dispõe de vários recursos para se expressar: palavras, gestos, expressões fisionômicas, símbolos. (ZUCHI, 2004)

Cada grupo possui a sua linguagem que, muitas vezes, é sua própria identidade. A língua é um meio direto que o ser humano utiliza para se expressar dentro de sua comunidade ou até mesmo fora dela. Desde os primórdios da humanidade, o homem tenta se comunicar através de símbolos, que são basicamente códigos, assim como a língua, que se utiliza através de palavras para demonstrar pensamentos e reações humanas. (PEREIRA; REIS; ROSA,2009)

Dessa forma, a comunicação tem um papel de grande importância na evolução da humanidade, pois é por meio dela que conhecemos a cultura de cada povo e a linguagem utilizada por cada comunidade. Para Terra e Nicola (apud ZUCHI, 2004, p.49), “A comunicação é o ato de tornar comum, conhecido.” A linguagem que 
um indivíduo expressa não pode ser criada e nem modificada, pois ela existe em virtude dos membros da comunidade. Assim sendo, um dos meios mais eficientes de que o homem dispõe é a linguagem (ZUCHI, 2004).

Para Boyer (1996), "O homem difere de outros animais de modo mais acentuado pela linguagem, cujo desenvolvimento foi essencial para que surgisse o pensamento matemático abstrato” (p.3).

Zuchi (2004) afirma que, “A linguagem humana é a capacidade do homem de comunicar-se por meio de uma língua" (p.49). Para que ocorra a comunicação, é indispensável à presença de elementos fundamentais como: o emissor, o receptor ou destinatário, a mensagem, o código, o referente e o canal (ZUCHI, 2004).

Segundo Zuchi (2004), o emissor é a pessoa que fala a mensagem; o receptor ou destinatário, a pessoa que ouve a mensagem; a mensagem, a conversa que pretende transmitir; o código, um conjunto comum ao emissor e ao destinatário formados por elementos e regras que permitem o entendimento da mensagem; o referente, o assunto da conversa, entre o emissor e o destinatário e o contexto linguístico da mensagem; o canal, meio físico do qual o emissor faz chegar à mensagem ao receptor e procura entendê-la.

Para Jakobson (1989):

[...] é mister uma perspectiva sumaria dos fatores constitutivos de todo o processo linguístico, de todo ato de comunicação verbal. O remetente envia uma mensagem ao destinatário. Para ser eficaz, a mensagem requer um contexto a que se refere (ou "referente", em outra nomenclatura algo ambígua) apreensível pelo destinatário, e que seja verbal ou suscetível de verbalização; um código total ou parcialmente comum ao remetente e o destinatário (ou, em outras palavras, ao codificador e ao decodificador da mensagem); e finalmente, um contato, um canal físico e uma conexão psicológica entre o remetente e o destinatário, que os capacitem a entrarem e permanecerem em comunicação (p.122- 123).

O primeiro linguista a instituir funções diferentes para a linguagem foi o alemão Karl Buhler, afirmando que existiam três funções básicas na comunicação: expressiva, informativa e estética. Mais tarde, o linguista russo Roman Jakobson duplicou essas funções, baseando-se nos seis elementos que compõe o processo comunicativo (CAMILLIS GIL, 2009). Essa modificação pode ser vista na figura a seguir:

Figura : Professor João Marcos Camillis Gil

REFERENTE

(contexto) 3

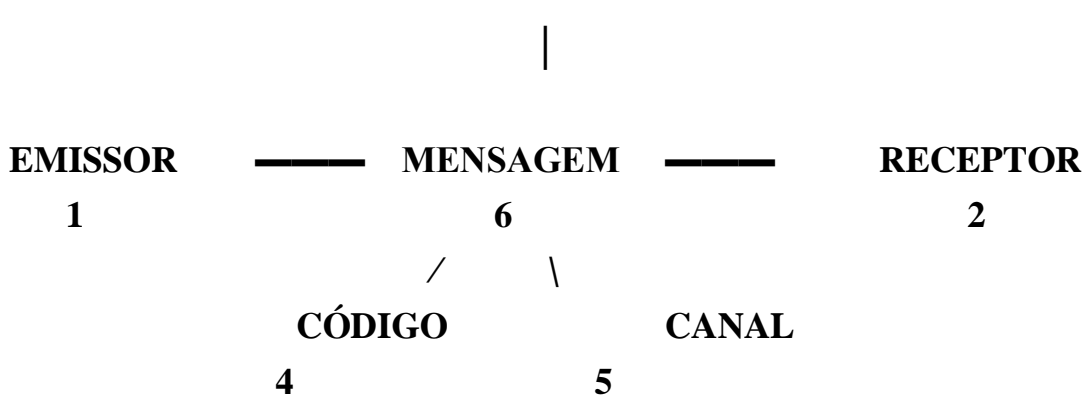

Fonte: www.cursoformaçao.com. br

Segundo Jakobson (1989), cada um desses elementos estaria ligado a um funcionamento diferente do sistema linguístico, fazendo com que a linguagem apresente as seguintes funções: referencial, emotiva, conativa, metalinguística, fática e poética, as quais serão abordadas a seguir. 
No que se refere à Função referencial, destacam-se como características a transmissão de informações, ideias, argumentos e conhecimento. A título de exemplo, podem-se citar os textos jornalísticos, revistas, livros didáticos, aulas, palestras e conferências. Essa função está ligada ao referente (ZUCHI, 2004).

A Função emotiva está ligada diretamente ao emissor. Essa função é caracterizada pela transmissão de sentimentos, emoções e sensações de cada pessoa. Nela, destacam-se as cartas e recados de amor e confissões apaixonadas, poemas e etc. (ZUCHI, 2004).

A Função conativa relaciona-se com o receptor por parte do emissor, procurando mudar seu comportamento, seduzi-lo e convencê-lo. Exemplos comuns dessa função são os anúncios publicitários, linguagens dos vendedores, as cantadas e a linguagem dos professores em sala de aula. (ZUCHI, 2004).

Quanto à Função metalinguística, pode-se dizer que há uma relação com o próprio código de comunicação usado. Exemplos comuns dessa função são discursos didáticos, críticas liberais e dicionários em geral. (ZUCHI, 2004).

A Função fática associa-se ao canal de comunicação, colocando-o em destaque e verificando seu funcionamento, ligando-o ou desligando-o. Alguns exemplos são as interjeições (oi, alô), saudações (Como vai, tudo bem?) e cumprimentos (bom dia!). (ZUCHI, 2004).

Por fim, no qual tange à Função poética, pode-se dizer que ela está ligada à própria mensagem que é colocada em destaque. $\mathrm{O}$ emissor, na escolha das palavras, tem um cuidado especial e elaborado, empregando imagens para expressar a mensagem. Um exemplo são os textos artísticos de modo geral. (ZUCHI, 2004).

Segundo Bordenave (apud CABRAL 2009):

A comunicação confunde-se com a própria vida. Temos tanta consciência de que comunicamos como de que respiramos ou andamos. Somente percebemos a sua essencial importância quando, por acidente ou uma doença perdemos a capacidade de nos comunicar.

Para D'Amaral (1977) afirma que "sendo a linguagem o lugar em que o homem se faz e se conhece, pode-se dizer que a linguagem é a casa do homem [...]" (p.74)

A linguagem possibilitou ao homem viver em sociedade de forma organizada e lidar com constantes mudanças, além de se expressar por meio de uma língua entre os membros da comunidade. A linguagem utilizada está relacionada com outras atividades sociais, como a necessidade de cada época que estabelece mudanças da linguagem falada. Isso denota que o dialeto falado está sempre acompanhando a evolução da humanidade. (ZUCHI, 2004).

A linguagem foi de extrema importância para o desenvolvimento de diversas áreas, e com a matemática não foi diferente. Através de uma linguagem própria, diversos avanços foram obtidos e, hoje, em certos casos nos quais exercícios só podiam ser resolvidos verbalmente, como ocorre com os problemas algébricos, foi criada uma simbologia que nos ajuda a resolvê-los. (PEREIRA; REIS; ROSA,2009).

Ainda quanto ao estudo da linguagem e sua importância na transmissão de informações, convêm igualmente destacar os trabalhos do pesquisador Raymond Duval. Esse cientista realizou importantes pesquisas sobre Registros de Representação, as quais têm sido cada vez mais utilizadas, especialmente aquelas relacionadas à aquisição de conhecimento e à organização de situações de aprendizagem. (PEREIRA; REIS; ROSA,2009)

Em suas pesquisas, Duyal trata principalmente do funcionamento cognitivo, implicando, sobretudo, na atividade Matemática e nos problemas de tal aprendizagem, estudando as representações e considerando-as de 
extrema importância para que ocorra o aprendizado matemático. Segundo Damm (2002), "Não existe conhecimento matemático que possa ser mobilizado por uma pessoa sem o auxílio de uma representação." (p.137).

De modo geral, a matemática não é de fácil compreensão, uma vez que possui uma linguagem própria. Tais complicações muitas vezes podem ser geradas pela complexidade própria da disciplina. "A matemática trabalha com objetos abstratos. Ou seja, os objetos matemáticos não são diretamente acessíveis à percepção, necessitando para sua apreensão o uso de uma representação." (DAMM, 2002, p. 137).

Duval (apud DAMM, 2002) estabelece três aproximações da noção de representação:

- As representações como representação subjetiva e mental: trata-se de estudar as crenças, as explicações e as concepções das crianças referentes a fenômenos físicos e naturais;

- As representações internas ou computacionais: são representações internas e não conscientes do sujeito. Ou seja, o sujeito acaba executando certas tarefas sem pensar em todos os passos necessários para a sua realização;

- As representações semióticas: a representação semiótica é externa e consciente do sujeito, sendo seu papel fundamental específico. (p 138-140).

Quanto as teorias de representação, Duval (apud DAMM, 2002) assim se manifesta:

[...] elas são relativas a um sistema particular de signos, linguagem natural, língua formal, escrita algébrica ou gráficos cartesianos, figuras, de um objeto matemático [...]. De onde a diversidade de representações para um mesmo objeto representado ou ainda a dualidade das representações semióticas: forma (o representante) e conteúdo (o representado) (p. 140).

As Representações Semióticas são consideradas Registros de Representação, desde que sejam satisfeitas as seguintes condições que são colocadas por Duval (apud DAMM, 2002):

- A formação de uma representação identificável;

- o tratamento;

- a conversão.

Estabelecendo-se as condições acima, os registros de representação passam a validar a compreensão de um conceito matemático. Para tanto, é necessário que o sujeito da aprendizagem consiga identificar o representante do objeto matemático em estudo, estabelecer o tratamento dentro do registro apresentado, que é, em outras palavras, desenvolver as operações ou algoritmos requeridos pelo tipo de representação e promover conversões entre os diferentes registros de representação do mesmo objeto. Contudo, em concordância com a Teoria dos Registros de Representação, a grande dificuldade da compreensão e aprendizagem dos objetos matemáticos é estabelecer a dicotomia entre representante e representado. (PEREIRA; REIS; ROSA,2009)

No entanto, quando há uma percepção sobre esta diferença, o sujeito da aprendizagem passa a olhar a representação, enxergando nesta o objeto representado. Nesse momento, é provável que o conceito sobre o objeto em questão esseja sendo mobilizado e compreendido. (PEREIRA; REIS; ROSA,2009)

Como exemplo, tomemos uma representação figural em que é representado no diagrama de coordenadas retangulares o gráfico de uma função do $1^{\circ}$ grau. É importante que o estudante consiga, ao visualizar a figura, mobilizar o conceito de função, concatenando suas características próprias como inclinação (coeficiente angular), coeficiente linear, raiz etc. Caso isto aconteça, pode-se prever que o estudante, nesse momento, consiga fazer a conversão entre outros registros de representação do mesmo objeto e, dessa forma, o conceito desse objeto passa a ter significado, sendo efetivamente compreendido (DAMM, 2002).

Contudo, para entendermos melhor como a comunicação por meio da linguagem ocorre na matemática e como seus aspectos devem ser trabalhados, faz-se necessário primeiramente entender o conceito de linguagem e linguagem matemática, os quais serão tratados a seguir. 


\section{O QUE É A LINGUAGEM?}

Para Chauí (2000), a linguagem nada mais é do que "um sistema de signos ou sinais usados para indicar coisas, para comunicação entre as pessoas e para expressão de idéias e sentimentos". (p.141). Ainda segundo essa pesquisadora, a definição de linguagem é muito simples, porém, esconde muitos problemas que os filósofos têm estudado ao longo dos tempos. Sobre essa definição de linguagem, Chauí (2000) assim se manifesta: "A linguagem é um sistema, isto é, uma totalidade estruturada, com princípios e leis próprios, sistema esse pode ser conhecido" (p.141).

Quanto à funcionalidade da linguagem, Chauí entende que "A linguagem indica coisas, isto é, os signos linguísticos (as palavras) possuem uma função indicativa ou denotativa, pois apontam para as coisas que significam" (2000, p.141).

Ela afirma ainda sobre a funcionalidade da linguagem que "a linguagem tem uma função comunicativa, isto é, por meio das palavras encontramos em relação com os outros, dialogamos, argumentamos, persuadimos, relatamos, discutimos, amamos e odiamos, ensinamos e aprendemos etc" (2000, p.141).

Para finalizar, Marilena Chauí (2000) define a linguagem como: "um sistema de sinais com função indicativa, comunicativa, expressiva e conativa". (p.141).

Assim, após os importantes aspectos sobre a linguagem e comunicação, passamos para a análise da linguagem matemática e sua história.

\section{A LINGUAGEM MATEMÁTICA E SUA HISTÓRIA}

Aventurando-se pelo campo histórico da matemática, pode-se perceber que já há muito tornou-se prática o uso de sinais gráficos para a representação e resolução de problemas matemáticos.

Há indícios que o uso de letras do alfabeto para representar entes matemáticos começou com grego Hipócrate de Quios (460- 380 a.C), numa obra de geometria que se perdeu, precursora de $O s$ Elementos de Euclides. Ele empregou letras do alfabeto grego para indicar pontos e retas de figuras geométricas (ZUCHI, 2004, P.52).

Zuchi (2004) constatou que quando se trata de cálculos que envolvem letras, a frequência dessa prática foi mais comum entre os autores hindus do que por gregos. "Os árabes do oriente empregavam símbolos algébricos a partir da publicação da aljabr Wa'l mugãbalah de Khorizmi." (p.52). Acredita-se que a palavra "álgebra" tenha se originado a partir desta publicação

Ao contrário do que constatamos hoje, como sendo um conteúdo matemático com vasta simbologia utilizada na resolução de vários problemas, a Álgebra, por estranho que possa parecer, demorou muito mais a contar com a simbologia adequada. Na matemática babilônica e egípcia, por exemplo, os problemas algébricos eram enunciados e resolvidos verbalmente. (ZUCHI, 2004, p.52).

Na história da matemática e do uso de sinais, destaca-se o matemático Diofanto de Alexandria, o primeiro a instituir e empregar a simbologia algébrica, autor da obra, "Arithmética".

Segundo Eves (2004):

A Arithimética é uma abordagem analítica da teoria dos números que eleva o autor á condição de gênio em seu campo. A parte remanescente do trabalho se dedica á resolução de 130 problemas, numa variedade considerável, que levam a equações do primeiro e do segundo graus. (p.207). 
É nessa obra, Arithmética, que Diofanto inseriu e usou metodicamente a simbologia por ele criada.

$\mathrm{O}$ símbolo $\mathrm{D}^{y}$, indicava o quadrado da incógnita, e o símbolo $\mathrm{K}^{y}$, indica o cubo da incógnita. Como a letra $\mathrm{b}$ (beta), indicava o numero 2 , então $\mathrm{D}^{y} \mathrm{~b}$ indicava o dobro do quadrado da incógnita. E, como a adição era por justaposição, como fazemos hoje com a multiplicação, a expressão diofantina $\mathrm{D}^{y} \mathrm{~b} \mathrm{~K}^{y} \mathrm{~b}$ corresponde ao que indicamos hoje por $2 \mathrm{x}^{2}+2 \mathrm{x}^{3}$ (IEZZI, apud ZUCHI 2004, P.52).

Além disso, "Diofanto de Alexandria teve uma importância enorme para o desenvolvimento da álgebra e uma grande influência sobre os europeus que posteriormente se dedicaram à teoria dos números." (EVES, 2004 p. 207).

Mesmo com a grande importância de Diofanto no desenvolvimento da Álgebra, podemos perceber que a simbologia usada por ele possuía algumas limitações relacionadas à falta de critério para diferenciar constante e incógnita. (PEREIRA; REIS; ROSA,2009)

Somente no século XVI, surgiu um critério para a solução desta limitação, graças a François Viéte ${ }^{1}$ (1560-1603).

Viéte inseriu uma notação tão simples quanto revolucionária: as quantidades variáveis eram representadas por vogais maiúsculas e as constantes por consoantes maiúsculas.

Pela primeira vez na história da matemática usam-se letras para representar coeficientes, o que tornou possível escrever uma equação para representar uma classe completa de equações. Se combinássemos a simbologia moderna com a convenção de Viéte, a expressão $\mathrm{BA}^{2}+\mathrm{CA}+\mathrm{C},(\mathrm{B} \neq 0)$, onde $\mathrm{A}$ indica a variável, e $\mathrm{B}, \mathrm{C}$ e $\mathrm{D}$ constantes quaisquer, representam a classe das equações do segundo grau. IEZZI (apud ZUCHI, 2004, p.52).

Desde Hipocrate de Quios até então, não se conhecia uma formalidade para a representação dos símbolos:

Antes de Viéte era comum se usarem letras ou símbolos diferentes para potências as várias de uma quantidade. Viéte usava a mesma letra, adequadamente qualificada; assim o que hoje se indica por $\mathrm{x}, \mathrm{x}^{2}, \mathrm{x}^{3}$ ele expressava por A, A quadratum, A cubum; mais tarde alguns escritores abreviaram essa notação para A, Aq, Ac.” (EVES, 2004, p.309).

Outro importante matemático, René Descartes, teve grande relevância no desenvolvimento da linguagem matemática.

Segundo Eves (2004),

A convenção do uso das primeiras letras de nosso alfabeto para indicarem constantes, e as últimas letras para indicar variáveis começou com Descartes em La géometie. Deve-se a ele também nossa atual notação para potências (como a ${ }^{3}, a^{4}$ e assim por diante) o que representa um grande avanço em relação a Viéte, e a percepção de que uma poderia representar qualquer quantidade, positiva ou negativa (p.388).

Zuchi (2004) afirma que "Hoje uma equação do segundo grau é representada por $a x^{2}+b x+c,(a \neq 0)$, seguindo a notação de René Descartes (1586-1650), que nada mais é que uma variante de notação de Viéte" (p.52).

Nesse sentido, esse autor assegura que, 
A formalização da matemática se deve também a seguidores de Descartes, como, Leibniz, Frege, Russel, mas o auge desta formalização que se tornou inclusive uma atitude filosófica ocorreu com o matemático Davis Hilbert (1862-1943) para o qual a formalização da matemática significaria uma aplicação da teoria dos conjuntos.(p.52).

Assim, após traçar um breve perfil do surgimento da linguagem matemática e sua história, passamos a tratar da comunicação na aula de matemática.

\section{COMUNICAÇÃO NA AULA DE MATEMÁTICA}

Nos dias atuais, a comunicação tem se expandindo em diversas áreas com caráter universal, como a música, a arte e outras manifestações culturais. Assim também, a linguagem matemática tem demonstrado seu alcance e universalidade. (KLUSENER, 2007).

A matemática, por ser uma ciência exata, assume de certa forma um caráter universal que tem origem histórica na busca rigorosa de fundamentos matemáticos. A busca pelo rigor caracteriza a matemática do século passado como uma ciência que contribuiu para criar uma dimensão de mundo própria e isolada que só os matemáticos entenderiam, e que acabou sendo cristalizada no século XX. (KLUSENER, 2007).

Além disso, a matemática forneceu o reforço do pensamento e ao mesmo tempo um instrumento eficaz na formação de uma sociedade moderna. Por outro lado, a linguagem matemática é importante em nosso meio de comunicação, pois é através dela que entendemos e compreendemos o contexto social e o mundo em que vivemos. (KLUSENER, 2007).

Para expor nossas ideias e estabelecer mentalmente os fenômenos que acontecem a nossa volta, é preciso compreendê-los e depois transformá-los através dos elementos de comunicação denominados símbolos, que compõem a linguagem matemática. (KLUSENER, 2007).

Para klusener (2007), "Aprender matemática é, em grande parte, aprender e utilizar suas diferentes linguagens - aritmética, geometria, álgebra, gráfica, entre outras.” (p.181). Atualmente, a linguagem matemática está presente em várias áreas do conhecimento e, assim sendo, é de estrema importância dominá-la, pois trata-se um saber necessário no dia-a-dia.

Portanto, é por meio da leitura e da escrita que nós seres humanos somos capazes de nos comunicarmos num contexto histórico-cultural e em uma linguagem universal. Para Danyluk (apud KLUSENER 2007), ler e escrever não diz respeito unicamente a nossa língua materna. (p.181). Temos que ter discernimento para compreender as formas humanas de interpretar, comentar e ponderar o mundo em nossa volta. E a matemática, ao longo de sua história, estabeleceu um sistema de comunicação e de representação que tem seus próprios códigos e linguagens (KLUSENER, 2007).

Nas escolas, atualmente, o ensino da matemática em sua prática pedagógica tem encontrado muitos fracassos. Os estudantes não conseguem expor as dificuldades e a grande maioria não gosta dessa disciplina. Alguns acabam abandonando a escola, e os que continuam acabam não entendendo a linguagem matemática, o que, para Corbalán (apud KLUSENER 2007), "significa conhecer e distinguir os números e talvez as quatro operações aritméticas, mas ser incapaz de uma análise crítica ou de tirar conclusões a partir de informações numéricas." (p.181). Contudo, apesar das dificuldades encontradas, muitos alunos conseguem alcançar um bom desempenho e um alto nível de escolarização.

Segundo Danyluk (apud KLUSENER, 2007),

[...] é fundamental compreender o sentido do fenômeno da alfabetização matemática. Ser alfabetizado em matemática é entender o que se lê e escreve, o que se entende a respeito das primeiras noções de aritmética, geometria e lógica, sem perder a dimensão social e cultural desse processo: é buscar o significado do ato de ler e de escrever, presentes na 
prática cotidiana. Para ser alfabetizado, basta simplesmente saber ler, escrever e contar [...] (p.181-182).

D’Ambrosio (apud KLUSENER 2007) afirma que é fundamental ver a educação matemática de uma forma que personifique o valor e a cultura da criança, isto é, sua etnomatemática. (p.182). A passagem da etnomatemática para a matemática pode ser vista como a passagem da linguagem oral para escrita. (KLUSENER, 2007, p.182). Sendo assim, a linguagem escrita faz parte do conhecimento oral que a criança possui e quando introduzir a linguagem escrita não deve abolir a oral. No entanto, a etnomatemática deve levar em conta o comportamento de cada aluno, buscando compreender a realidade ao longo do processo de sua vida. (KLUSENER, 2007).

Atualmente, os professores precisam assumir um compromisso sério com a educação. Devem ser os agentes desse processo de mudanças, buscando participar mais da vida de seu aluno, reconhecendo suas habilidades para motivá-lo a ampliar seu conhecimento, bem como ajudá-lo a superar as dificuldades encontradas no seu cotidiano (KLUSENER, 2007).

A matemática tem sido ensinada de maneira a não dar privilégio as suas expressões - oral, escrita e visual - mas destacando-se os códigos escritos. Tal procedimento ocorre por causa da metodologia ensinada em que não se possibilita o uso de regras, não se desenvolve a linguagem em todos os seus aspectos. $\mathrm{O}$ vocabulário utilizado é basicamente limitado e restritivo. Tais fatores só fazer aumentar a distância entre a matemática ensinada na escola e a realidade matemática de nossos alunos, o que tem sido um problema (KLUSENER, 2007)

Ao entrar na escola, a criança sabe falar, tem um vocabulário próprio, mas não sabe escrever. Assim, pretende-se que ela escreva utilizando-se da linguagem simbólica, não lhe dando possibilidade de desenvolver suas expressões naturais. (KLUSENER, 2007).

Fernando (apud, (KLUSENER, 2007) defende que:

[...] formas descritivas que substituem, num primeiro momento, certos termos próprios da linguagem matemática evidenciada pela complexidade dos símbolos. Nesse procedimento, temos esquecido que se pensa em palavras e não em símbolos, e que é necessário passar pela experimentação do material para posterior verbalização, tanto oral quanto escrita, para só então chegar ao processo da linguagem simbólica (p 184).

Portanto, devemos lembrar que os problemas aprendidos em matemática, como meio de comunicação, são diferentes da língua materna, pois a linguagem matemática não é utilizada constantemente e precisa ser aprendida e praticada. (KLUSENER, 2007).

Somente a prática constante, bem como a inserção consciente da linguagem matemática por parte dos docentes é capaz de tornar o seu processo de assimilação mais natural e significativo, fazendo com que a matemática possa finalmente ser vista como o meio de comunicação que é. (PEREIRA; REIS; ROSA,2009)

\section{A MATEMÁTICA COMO MEIO DE COMUNICAÇÃO}

A comunicação é um elemento essencial na vida dos seres humanos. Zuchi (2004) comenta que "Ensinar e aprender são atos iminentemente comunicativos, que envolvem diversos agentes, entre os quais, destacam-se professores e alunos" (p.53).

Menezes (2000) afirma que: 
Além de a comunicação ser um meio no qual se ensina e se aprende, é também através desse ensino que os alunos adquirirem competências comunicativas, que no caso da matemática, se interagem juntamente com outras competências como a resolução de problemas, o raciocínio.

Smole; Diniz (apud FELISBERTO; LOPES 2009) postulam que,

[...] durante uma situação de resolução de problemas e comunicação o aluno aprende matemática, desenvolve procedimentos, modos de pensar, desenvolvem habilidades básicas como verbalizar, ler, interpretar e produzir textos em diferentes áreas do conhecimento que podem estar envolvidas em uma situação. Isso indica que a resolução de problemas deve ser vista como uma metodologia de ensino, e que o professor de matemática ao utilizar-se dela estará contribuindo para o desenvolvimento de habilidades leitoras. (p.95).

Não podemos deixar de salientar ainda que ler, escrever e interpretar são fundamentos necessários para qualquer área do conhecimento. Nacarato; Lopes (apud FELISBERTO; LOPES 2009) afirmam que no ensino e aprendizagem da matemática, os aspectos linguísticos precisam ser considerados inseparáveis dos aspectos conceituais para que aconteça, a comunicação, bem como a aprendizagem (p.119).

A linguagem geralmente expressa em enunciados de problemas e questões é exposta de maneira a dificultar a compreensão dos alunos. Para que a compreensão matemática flua, necessitamos da linguagem de nosso dia-a-dia, modificando o sentido das palavras, buscando assim a aprendizagem por parte dos discentes.

Para Fonseca; Cardoso (apud OLIVEIRA, 2009), no trabalho com crianças, deve-se atentar para as dificuldades de leitura apresentadas pelos alunos:

A dificuldade que os alunos encontram em ler e compreender textos de problemas estão, entre outros fatores, ligados à ausência de um trabalho específico com o texto do problema. $\mathrm{O}$ estilo nos quais os problemas de matemática geralmente são escritos, a falta de compreensão de um conceito envolvido no problema, o uso de termos específicos da matemática que, portanto, não fazem parte do cotidiano do aluno e até mesmo palavras que têm significado diferentes na Matemática e fora dela - total, diferença, ìmpar, média, volume, produto - podem constituir-se em obstáculos para que ocorra a compreensão (p.64).

Menezes (2000) afirma que a comunicação na aula de matemática assume ainda uma importância suplementar, uma vez que esta disciplina dispõe de uma linguagem própria, permitindo comunicar ideias com precisão, clareza e economia. Aprender matemática exige linguagem e interação, pois os conceitos, representações e informações existem entre as pessoas através dos recursos de comunicação. (GONÇALVES; SILVA; SANTO, 2009). Assim, torna-se necessário que seja estimulada a escrita e a oralidade na comunicação.

De acordo com Smole (apud OLIVEIRA, 2009), a primeira característica da linguagem matemática é o fato de que ela, como linguagem cientifica que é, não possui oralidade própria, está totalmente voltada para a escrita, explicando então a necessidade de um maior esforço no sentido de torná-la mais acessível. A segunda característica é que ela é essencialmente o estabelecimento de relações entre sinais, os quais nem sempre são compreendidos ou trabalhados adequadamente.

Assim, afirmam os PCN (2000) que se para a aprendizagem da escrita o suporte é a fala, que funciona como um elemento de mediação na passagem do pensamento para a escrita, na aprendizagem da matemática a expressão oral também desempenha um papel fundamental (p.64).

Isso se faz presente no dia-a-dia na sala de aula, espaço em que muitas vezes professores e alunos não conseguem falar a mesma língua, pois a dificuldade encontra-se quase sempre na oralidade e na dificuldade de decifrar os códigos matemáticos. 
Carrasco (apud OLIVEIRA, 2009) sugere dois recursos para problemas de leitura e de letra. Um deles é mencionar e escrever, em linguagem usual, os resultados matemáticos. A outra solução seria auxiliar as pessoas a dominarem as ferramentas de leitura, ou seja, a entenderem a acepção dos símbolos, sinais e notações.

Ao ler um símbolo matemático, é preciso entender o significado atribuído a ele. O símbolo traduz uma ideia e se refere a alguma coisa (DANYLUK, 1991, p.40).

A decodificação prejudica a compreensão dos símbolos. Vejamos um exemplo:

Quando deparamos com uma adição, sabe-se o significado do sinal da operação (+), mas nem sempre entende o que significa "operação". É possível efetuar a adição $5+3$, porém pode ser feito de modo mecânico. Sendo assim, para que a leitura não seja uma decodificação de sinais, é preciso que se entenda que na operação é realizada uma transformação. Isso significa, que o 5 é o estado inicial da operação e o 3 o operador que age sobre o estado inicial, dando origem a 8, que é o estado final da operação. Só quando o aluno chega a essa compreensão e consegue interpretar o texto em que está lendo, é que ele começa a entender o sentido dos símbolos. (DANYLUK, 2000, p.41).

O símbolo tem um significado que transcende o objeto simbolizado, por isso não é uma mera formalidade. (CENTURIÓN, 1994, p.56).

Na matemática, ao ler um texto, deparamo-nos com símbolos. Para que o texto seja compreendido, devemos nos familiarizar com os símbolos que nele estão inseridos. Também é preciso considerar que devemos encontrar sentido nos símbolos e nas formas matemáticas para que possamos entender tais formas e raciocinarmo-nos com elas. (DANYLUK, 2000).

Assim, é de extrema importância encontrar sentido nos símbolos matemáticos e compreender os seus significados para conseguir raciocinar e expressar na linguagem específica da matemática. (KLEIN e GIL, 2003).

Salienta-se ainda que os símbolos numéricos também transmitem informações, em geral de modo mais rápido e econômico. (Oliveira, 2009). Os símbolos matemáticos podem representar informações, ideias ou resultados.

Todo símbolo corresponde a um complexo sonoro e significativo que o simboliza e que serve para designar e comunicar, diz Santos (apud OLIVEIRA, 2007 p.107). No processo de compreensão dos conceitos matemáticos, fica evidenciada a responsabilidade que o professor deve assumir perante seus alunos para leválos à compreensão dos símbolos por meio de uma linguagem acessível, só então partindo para um trabalho mais consciente com a linguagem matemática.

\section{O PAPEL DOS PROFESSORES}

A linguagem empregada em livros didáticos parece estar além da capacidade de compreensão de nossos alunos, assim, cabe ao professor tornar a matemática inteligível, ou seja, transcrevê-la em uma linguagem acessível a todos os interessados em aprendê-la, possibilitando assim a interação (MAZZEI, 2009).

Professores de matemática preocupam-se com a leitura de enunciados de questões que em muitas vezes acabam acarretando e trazendo insucessos na realização de atividades matemáticas. Recorrem, geralmente, a um professor de língua Portuguesa, com leituras de textos para aprendizagem de pequenas interpretações, o que não ataca a questão fundamental: "dificuldades com problemas e com textos matemáticos" (OLIVEIRA, 2009).

Segundo Vigostsky (1998),

O desenvolvimento dos conceitos, ou dos significados das palavras, pressupõe o desenvolvimento de funções intelectuais: atenção deliberada, memória lógica, abstração, 
capacidade para comparar e diferenciar. Esses processos psicológicos complexos não podem ser dominados apenas através da aprendizagem inicial. A experiência prática mostra também que o ensino direto de conceitos é impossível e infrutífero. O professor que tenta fazer isso geralmente não obtém qualquer resultado, exceto o verbalismo vazio, uma repetição de palavras pela criança, semelhante à de um papagaio, que simula um conhecimento dos conceitos correspondentes, mas que na realidade oculta um vácuo (p.104).

De acordo com Menezes (2009), o professor, como principal responsável pela organização do discurso da aula, tem aí um papel fundamental, colocando questões, proporcionando situações que favoreçam a ligação da Matemática à realidade, estimulando a discussão e a partilha de ideias.

No entanto, valorizar uma dinâmica comunicativa na sala de aula não significa apenas procurar um ambiente agradável, introduzir novas tarefas, ou incentivar a participação dos alunos. É necessário que o professor estimule o interesse dos alunos, ajudando-os a empenhar-se na própria aprendizagem e a ganhar autoconfiança para que, por conta própria, sejam capazes de lidar não somente com a linguagem matemática, mas também com os diferentes tipos de códigos presentes na vida cotidiana. (MARTINHO, 2009).

\section{CONSIDERAÇÕES FINAIS}

O objetivo desse trabalho foi enfatizar a linguagem matemática na constituição do conhecimento matemático almejando despertar nos educadores da área em foco um maior interesse pelo assunto.

Assim, destacamos a comunicação e linguagem que fazem parte da vida do ser humano desde o surgimento da humanidade e enfatizamos os vários recursos que o homem utiliza para se expressar como as palavras, gestos, expressões fisionômicas e os símbolos (ZUCHI, 2004).

Dessa forma, por meio do estudo da simbologia matemática, torna-se possível "encontrar respostas para as suas dúvidas e também compreender o porquê desse processo" (ZUCHI, 2004, P.51).

Por fim, é importante voltar a atenção para a comunicação na aula de matemática, repensando os métodos utilizados para que possa haver uma compreensão dos símbolos e expressões matemáticas, ou seja, é necessário procurar facilitar a comunicação dos conteúdos matemáticos em sala de aula, papel esse que pertence ao professor. Na busca de tornar a matemática inteligível, ou seja, transcrevê-la em uma linguagem acessível a todos os interessados em aprendê-la, possibilitando assim a interação, os docentes tornam-se os principais agentes (MAZZEI, 2009).

Em síntese, retomando nossa questão apresentada nas considerações iniciais, concluíi-se que a linguagem matemática é fundamental ao desenvolvimento do espírito critico do aluno e, como docentes dessa disciplina, os professores são os responsáveis por esse crescimento. (PEREIRA; REIS; ROSA,2009)

\section{REFERÊNCIAS}

ANDRADE, M. M. de. Como preparar trabalhos para curso de Pós-Graduação: noções práticas. 5. ed. São Paulo: Atlas, 2002.

BOYER, C.. B. História da matemática: revista por UTAC. Merzbach; tradução Elza F. Gomide. 2.ed. São Paulo: Edgard Blucher, 2003.

BRASIL, Secretaria de Educação Fundamental. Parâmetros Curriculares Nacionais: matemática. Brasília: a Secretaria, 2000. 
CABRAL, M.. As funções da linguagem. Equipe Brasil escola. Disponível em:

http://www.cursoformaçao.com.br/ htmlcf/imagens/artigos / 58/ $20 \%$ da $\% 20$ linguagem $\% 5 \mathrm{~b} 3 \% 5 \mathrm{~d}$ doc

Acesso em: 27maio 2009.

CAMILLIS GIL, J. M.de. Funções da linguagem. Disponível em <http://www.cursoformaçao.com.br/ htmlcf/imagens/artigos / 58/ $20 \%$ da \% 20 linguagem \% 5b3\% 5 d doc >. Acesso em: 11 mar. 2009

CARRASCO, L. H. M.. Ler, escrever e compreender a matemática, ao invés de tropeçar nos símbolos. In: NEVES, I.C.B. et al. (orgs). Ler e escrever: compromisso de todas as áreas. 8. ed. Porto Alegre: UFRGS, 2007. p. 194 - 205. (Série continuação continuada).

CHAUÍ, M.. Convite a filosofia. 12.ed.. 2ª impressão. São Paulo: Ática, 2000.

D’AMARAL, M. T.. Filosofia da comunicação e da linguagem. Rio de Janeiro: Civilização brasileira,1977.

DAMM, R. F.. Registros de representação. In: MACHADO, S. D.A. et al. Educação matemática: uma introdução São Paulo: EDUC, p.135-153.2002.

DUARTE, Paulo César Xavier. Desenvolvendo cidadãos atuantes por meio do ensino da Matemática: o caso do programa PAIE do Governo de Minas Gerais. 2004. Dissertação (Mestrado). Programa de PósGraduação em Educação Matemática, Unesp, Rio Claro.

FARACO, Carlos Emilio; MOURA, Francisco Marto de. Língua e literatura. 39.ed. $2^{\circ}$ grau. São Paulo: Ática, V.1,1997.

: Língua e Literatura. 39. ed. $2^{\circ}$ grau. São Paulo: Ática, V.1,1989.

FELISBERTO, K.G. de L.; LOPES, C. E.: Leitura e escrita na aprendizagem matemática. Disponível em < http:// www.sbem.com.br/files/ix enem/Poster/Trabalhos/PO30201417880T.doc >. Acesso em: 27 maio 2009.

GONÇALVES, K. L. N.; SILVA, F. H. S. da; SANTOS, A. O. de E.. Comunicação Interativa: uma perspectiva para o ensino de matemática. Disponível em $\langle$ http:// www2.rc.unesp.br/eventos/m >. Acesso em 27 maio 2009.

HOWARD, E.. Tradução à história da matemática; tradução: Hygino H. Domingues. Campinas: Unicamp, 2004.

HUNTER, J. C. Monge e o executivo: uma história sobre a essência da liderança. 15. ed. Rio de Janeiro: Sextante. 2004.

JAKOBSON, R.. Linguística e comunicação. Tradução de Isidoro Blikstein e José Paulo Paes. São Paulo: Cultrix, 1989.

KLAIN, A. M.; GIL, M. da C. S.. Ensino de Matemática. Curitiba: Iesde, 2003.

KLUSENER, R. Ler, escrever e compreender a matemática, ao invés de tropeçar nos símbolos. In: NEVES, I.C.B. et al. (orgs). Ler e escrever: compromisso de todas as áreas. 8 ed. P. 179-193. Porto Alegre: UFRGS, 2007. (Série continuação continuada).

LIMA, M. C.. Monografia: a engenharia da produção acadêmica. São Paulo: Saraiva, 2004.

LUDKE, M.; ANDRÉ, M. E. D. A. Pesquisa em educação: abordagens qualitativas. São Paulo: Pedagógica e Universitária, 1986.

MARTINHO, M. H.: PONTE, J. P. da. A comunicação na sala de aula de matemática. Disponível em < http://www.educ.fc.ul.pt/docentes/jponte/fdm/textos/Martinho-Ponte_05\%20SIEM_.pdf> Acesso em: 14 ago.2009. 
MAZZEI, L. D.. A linguagem nas aulas de matemática. UFRGS. Disponível em $\langle$ http://www.sbem.com.br/files/ix_enem/Comunicacao_Cientifica/Trabalhos/CC51970465034T.doc >. Acesso em: 13 maio 2009.

MENESES, L.. Matemática, linguagem e comunicação. Revista Milennium, Instituto Politécnico de Viseu, n.20, out. 2000. Disponível em< http://www.ipv.pt/millenium/20_ect7.htm>. Acesso em: 21 maio 2008.

OLIVEIRA, N.. Linguagem, comunicação e matemática. Faculdade Integrada de Jacareí. Disponível em <http://www.cursoformaçao.com.br $/ \mathrm{html} \mathrm{CF/imagens/artigos/58} \mathrm{funçoes} \% 20$ da $\% 20$ linguagem $\% 5 \mathrm{~b} 3 \% 5$ D. doc >. Acesso em: 20 fev.2009.

OLIVEIRA, R. L. de. E amargo vira doce... fazendo contas de cabeça. In: FIORENTINI, Dario; JIMENEZ, Afonso (org); Histórias de aulas: compartilhando saberes profissionais. Campinas: FE: CEMPEM, 2003.

PEREIRA, C. H.; REIS, D.C; ROSA, A.C. A linguagem no ensino de matemática. 2009. Trabalho de Conclusão de Curso. (Licenciatura em Matemática). : Universidade do Vale do Sapucaí.

RUDIO, F. V.. Introdução ao projeto de Pesquisa Científica. 30. Ed. Petrópolis: Vozes, 2002.

SIQUEIRA, E. A.; CASTRO, M. A. de. Aprender e ensinar: relações entre o desenvolvimento cognitivo e a prática docente. 2008. 104 f. Trabalho de Iniciação Científica Universidade do Vale do Sapucaí, Pouso Alegre.

VIGOTSKY, L.S.. Pensamento e linguagem. Tradução Jéferson Luiz Camargo. São Paulo: Martins Fontes, 1998.

ZUCHI, I. A importância da linguagem no ensino de matemática. Educação Matemática em Revista. Revista da Sociedade Brasileira de Educação Matemática. Ano11, n. 16, maio 2004. 